\title{
Surgical versus non-surgical treatment of chronic low back pain: a meta-analysis of randomised trials
}

\author{
T. Ibrahim • I. M. Tleyjeh • O. Gabbar
}

Received: 29 July 2006/Revised: 19 August 2006 /Accepted: 21 August 2006 /Published online: 21 November 2006

(C) Springer-Verlag 2006

\begin{abstract}
We performed a meta-analysis of randomised controlled trials to investigate the effectiveness of surgical fusion for the treatment of chronic low back pain compared to non-surgical intervention. Several electronic databases (MEDLINE, EMBASE, CINAHL and Science Citation Index) were searched from 1966 to 2005 . The metaanalysis comparison was based on the mean difference in Oswestry Disability Index (ODI) change from baseline to the specified follow-up of patients undergoing surgical versus non-surgical treatment. Of the 58 articles identified, three studies were eligible for primary analysis and one study for sensitivity analysis, with a total of 634 patients. The pooled mean difference in ODI between the surgical and non-surgical groups was in favour of surgery (mean difference of ODI: $4.13,95 \% \mathrm{CI}:-0.82$ to $9.08, p=0.10, \mathrm{I}^{2}=$ 44.4\%). Surgical treatment was associated with a $16 \%$ pooled rate of early complication ( $\left.95 \% \mathrm{CI}: 12-20, \mathrm{I}^{2}=0 \%\right)$. Surgical fusion for chronic low back pain favoured a marginal improvement in the ODI compared to nonsurgical intervention. This difference in ODI was not
\end{abstract}

T. Ibrahim $(\bowtie)$

Department of Orthopaedic Surgery, Leicester General Hospital,

Gwendolen Road,

Leicester LE5 4PW, UK

e-mail: ti11@le.ac.uk

I. M. Tleyjeh

Department of Medicine, Mayo Clinic College of Medicine,

Mayo Clinic,

200 First Street SW,

Rochester, MN 55905, USA

O. Gabbar

Department of Orthopaedic Surgery, Leicester Royal Infirmary,

Infirmary Square,

Leicester LE1 5WW, UK statistically significant and is of minimal clinical importance. Surgery was found to be associated with a significant risk of complications. Therefore, the cumulative evidence at the present time does not support routine surgical fusion for the treatment of chronic low back pain.

Résumé Méta-analyse randomisée pour étudier la réalité de la fusion chirurgicale pour lombalgies chroniques comparée à l'évolution sans chirurgie. Plusieurs fichiers électroniques (Medline, Embase, Cinahl et Science citation index) ont été étudié de 1996 à 2005. La comparaison était basée sur les modifications de l'index d'Owestry (ODI) après traitement chirurgical ou non chirurgical. Trois études sur 58 articles étaient utilisables pour une première analyse et une étude pour une analyse fine, avec un total de 634 patients. Les différences de l'index mesuré étaient en faveur de la chirugie (différence moyenne de l'index ODI: 4,13; IC de 95\%:-0,82 à 9,$\left.08 ; \mathrm{p}=0,10 ; \mathrm{I}^{2}=44,4 \%\right)$. Le traitement chirurgical s'accompagnait de $16 \%$ de complications précoces (IC de 95\%:12-20\%, $\mathrm{I}^{2}=0 \%$ ). La fusion chirugicale pour lombalgies chroniques améliore de façon non significative l'index de Oswestry par rapport au traitement non chirurgical et elle a un risque plus grand de complications.

\section{Introduction}

Low back pain is a common symptom affecting $70-85 \%$ of the population at some stage in their life [1]. When it persists for longer than three months, it is classified as chronic. Chronic low back pain is prevalent in $23 \%$ of the population [2] and is the most common cause of activity limitation in people younger than 45 years of age [1]. In addition to the physical symptoms endured by these patients, chronic low back pain poses a major economic problem due to their frequent use of health services and absence from work. 
The management of chronic low back pain remains controversial with a variety of treatment options available $[14,26]$. The traditional approach is non-surgical treatment combining physiotherapy and analgesia. Failure of the nonsurgical treatment leads to alternative options, such as a variety of surgical approaches to achieve spinal fusion [15, $18]$ with various results $[5,22,29]$.

The indications for spinal fusion and how it should be performed for the relief of chronic low back pain remain unclear. The aim of surgical fusion is to reduce pain and decrease disability, and the underlying rationale is that the pain arises from a degenerative motion segment and, consequently, fusion should eliminate motion and subsequent pain $[5,13,26]$.

During recent decades, surgical fusion of the lumbar spine for chronic low back pain has been increasingly performed on patients [4]. In 2001, over 122,000 lumbar fusions were performed in the United States for degenerative conditions of the lumbar spine. This represents a $220 \%$ increase in fusions per 100,000 since 1990 [7]. These increases were not associated with clarified indications or improved efficacy, suggesting a need for better data on the efficacy of various fusion techniques for various indications. The lack of consensus on whether surgical or nonsurgical treatment should be offered to patients has prompted several randomised controlled trials (RCTs) [3, $8,9,12,19,24]$.

In order to investigate the effectiveness of fusion as a treatment for chronic low back pain, we carried out a systematic review of the literature and a meta-analysis of RCTs and compared our findings to those of non-surgical intervention following the Quality of Reporting of Metaanalyses (QUOROM) [23] guidelines.

\section{Methods}

Identification of relevant literature

A literature search to identify all published randomised controlled trials comparing surgical fusion and non-surgical intervention for the treatment of chronic low back pain was performed with the help of an experienced medical librarian. The databases that were searched included MEDLINE (1966-October 2005), EMBASE (1980-October 2005), CINAHL (1982-October 2005), Science Citation Index (1970-October 2005) and the Cochrane registry of clinical trials.

The following key words were used for the search: low back pain, physical therapy, physiotherapy, rehabilitation, cognitive therapy, surgery, spinal fusion, spinal stabilisation, randomised controlled trial, random allocation, randomisation and clinical trial.
Two authors independently reviewed abstracts of all the references identified. Any study that could be relevant based on findings that were described in the respective abstract was reviewed in full text. Bibliographies and review articles were reviewed manually for additional citations. There was no restriction to the language of the publication. We did not seek unpublished investigations.

Inclusion criteria

Only RCTs comparing surgical and non-surgical treatments for chronic low back pain were considered for inclusion. The types of treatment included surgical (spinal fusion with or without instrumentation) and non-surgical (physical therapy with or without cognitive therapy) interventions. The trials must have reported an Oswestry Disability Index (ODI) as an outcome measure. The ODI has ten questions on pain and pain-related disability in activities of daily life and social participation and is patient-administered. The sum is calculated as a percentage, with $0 \%$ representing no pain and disability and $100 \%$ representing the highest level (worst) of possible pain and disability. The ODI is a valid condition-specific outcome measure of spine-related disability [10]. We excluded RCTs with unique primary outcomes where the pooling of results was not possible [19].

\section{Data collection}

A data collection form was developed and used to retrieve information on relevant features and results. Two authors independently extracted data. The data retrieved included the following items: study characteristics, intervention, outcome definition, sample size, mean difference in ODI change from baseline to follow-up of patients undergoing surgery versus those undergoing non-surgical treatment with a respective standard error or $95 \%$ confidence interval (CI) and the number of patients with early complications (within two weeks) from surgery. The two authors independently assessed the methodological quality of the selected studies, and any disagreement that arose was discussed and resolved by consensus.

\section{Statistical analysis}

The meta-analytic comparison was based on the mean difference in ODI change from baseline to follow-up of patients undergoing surgery versus those undergoing nonsurgical treatment. The mean difference in ODI with the $95 \%$ CI were extracted from studies in all of the papers [3, $9,12]$. One study included in the sensitivity analysis did not report the mean change from baseline to follow-up [8]. Pooled estimates of the mean difference in ODI were obtained by combining the separate estimates of inverse 
variance-weighted log mean difference estimates from each study. We performed sensitivity analyses by repeating the meta-analysis using the imputed mean difference in ODI change in the study by Fairbank et al. [9] that had $>15 \%$ loss to follow-up. Additional sensitivity analyses were repeated by including the study by Ekman et al. [8] since it involved a different patient population (patients with adult isthmic spondylolisthesis). For this study [8], we used the mean difference in ODI at follow-up between the surgical and non-surgical groups. In a randomised trial, mean differences based on changes from baseline can usually be assumed to be addressing exactly the same underlying treatment effects as analyses based on final measurements [21].

We also pooled the early complication rates among patients undergoing spinal fusion surgery. Complications rates and their $95 \% \mathrm{CI}$ were obtained by dividing the number of patients developing complications by the total number of patients undergoing surgery. Pooled estimates of the complication rates were then obtained by combining the separate estimates of inverse variance-weighted log complication rates from each study. All meta-analyses were performed using a random-effect model [6].

Between-study inconsistency was quantified by means of $\mathrm{I}^{2}=[(\mathrm{Q}-\mathrm{df}) / \mathrm{Q}] \times 100 \%$, where $\mathrm{Q}$ is the chi-squared statistic and $d f$ is its degrees of freedom [16]. $\mathrm{I}^{2}$ defines the variability percentage in effect estimates that is due to heterogeneity rather than to sampling error (chance). A value $>50 \%$ represents substantial heterogeneity. All analyses were performed with REVMAN ANALYSES ver. 4.2.7 (2004, the Cochrane Collaboration).

\section{Results}

Studies meeting inclusion criteria for analysis

Figure 1 summarises the process of identifying eligible studies. The search resulted in identifying six studies, three of which were found to be eligible for primary analysis. The fourth [8] was included in the sensitivity analysis and the fifth [24] study was a duplicate study reporting on the same set of patients with isthmic spondylolisthesis. The sixth study did not report an ODI as an outcome measure [19]. The kappa statistics for interobserver agreement on study eligibility was 1.0 .

Study characteristics

Table 1 summarises the characteristics of the four studies included in our primary and sensitivity analyses. Taken together, the studies included a total of 634 patients, with individual sample sizes ranging from 61 to 289 patients.

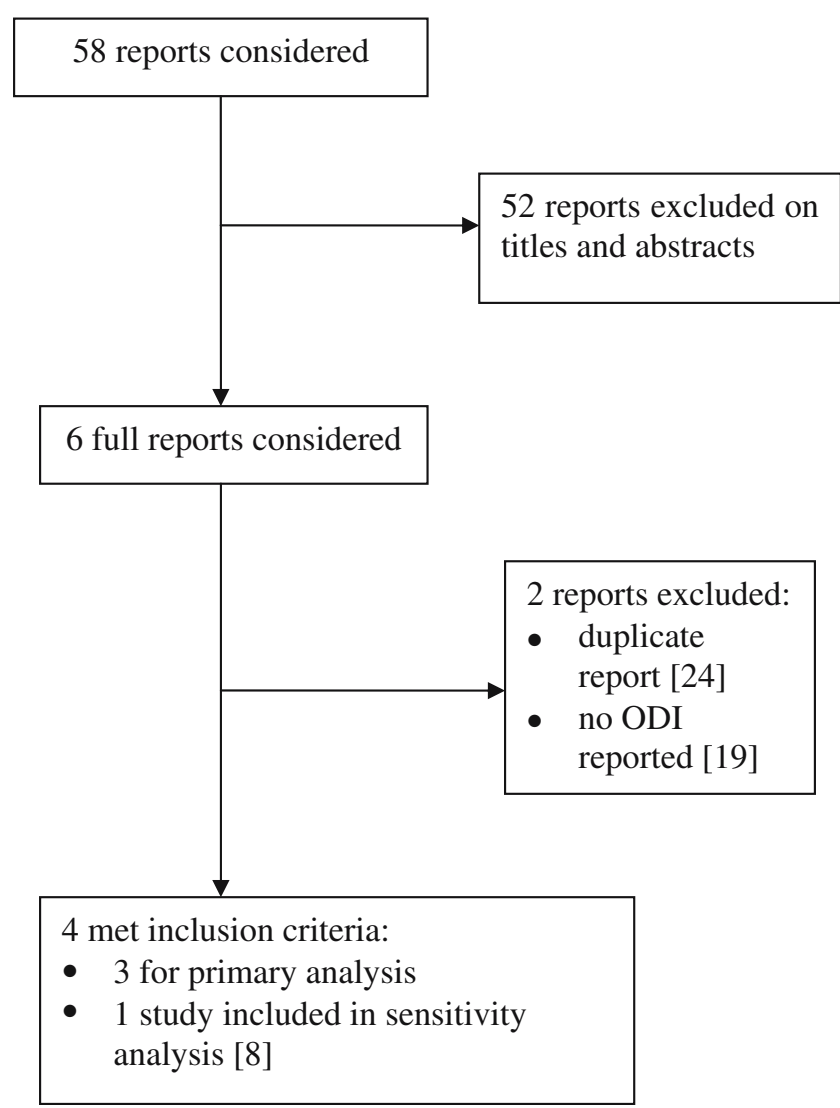

Fig. 1 Flow diagram of eligible studies. ODI Oswestry Disability Index

One of the studies recruited patients with a history of low back pain that had persisted for more than 12 months [3], and two of the studies had recruited patients with low back pain persisting at least two years [9, 12]. Ekman et al. [8] recruited patients with isthmic spondylolisthesis. All of the patients were adults. Surgical treatment involved surgical fusion with or without instrumentation or flexible stabilisation, and non-surgical treatment involved exercise programs with or without cognitive therapy. The primary outcome in all studies was assessed using the difference in ODI from baseline to follow-up. In the study by Ekman et al. [8], only the ODI at follow-up was reported.

Quality assessment

We assessed the quality of the studies in two ways. Firstly, randomised controlled trials were judged according to the key validity components that address biases in selection, performance, detection and sample attrition [17]. Table 2 summarises the different domains of study quality. The kappa statistics for interobserver agreement on these quality domains was 1.0.

Secondly, we assessed quality by using ten criteria taken from the Cochrane Back Review Group [30]. All studies 
Table 1 Characteristics of the randomised controlled trials included in this study

\begin{tabular}{|c|c|c|c|c|c|c|}
\hline $\begin{array}{l}\text { Source, year, } \\
\text { country }\end{array}$ & $\begin{array}{l}\text { Age of } \\
\text { patients: } \\
\text { range in } \\
\text { years }\end{array}$ & $\begin{array}{l}\text { Number } \\
\text { of patients } \\
\text { at follow- } \\
\text { up }\end{array}$ & Type of surgery & $\begin{array}{l}\text { Type of non- } \\
\text { surgical } \\
\text { treatment }\end{array}$ & $\begin{array}{l}\text { Follow- } \\
\text { up } \\
\text { period }\end{array}$ & Outcomes other than ODI \\
\hline $\begin{array}{l}\text { Fairbank et al. } \\
\text { [9], 2005, UK } \\
\text { (Multi-centre) }\end{array}$ & $18-55$ & 284 & $\begin{array}{l}\text { Spinal fusion with some } \\
\text { cases of flexible } \\
\text { stabilisation }\end{array}$ & $\begin{array}{l}\text { Intensive } \\
\text { rehabilitation } \\
\text { and Cognitive } \\
\text { therapy }\end{array}$ & 2 years & $\begin{array}{l}\text { Shuttle Walking Test; Short Form } 36 \text { (SF-36). } \\
\text { No significant difference in shuttle walking } \\
\text { test and SF-36 }\end{array}$ \\
\hline $\begin{array}{l}\text { Fritzell et al. } \\
\text { [12], 2001, } \\
\text { Sweden } \\
\text { (Multi-centre) }\end{array}$ & $25-65$ & 289 & $\begin{array}{l}\text { Posterolateral fusion } \\
\text { (PLF) or PLF with pedicle } \\
\text { screws or circumferential } \\
\text { fusion }\end{array}$ & $\begin{array}{l}\text { Physical } \\
\text { therapy }\end{array}$ & 2 years & $\begin{array}{l}\text { Visual Analogue Scale (VAS); Million Visual } \\
\text { Analogue Scale (MVAS); General Function } \\
\text { Score (GFS); Zung Depression Scale (ZDS); } \\
\text { Overall Assessment; Work Status. No } \\
\text { significant difference in ZDS. Significant } \\
\text { difference in VAS, MVAS, GFS, overall } \\
\text { assessment and work status in favour of } \\
\text { surgical group }\end{array}$ \\
\hline $\begin{array}{l}\text { Brox et al. [3], } \\
\text { 2003, Norway }\end{array}$ & $25-60$ & 61 & PLF with pedicle screws & $\begin{array}{l}\text { Physical and } \\
\text { Cognitive } \\
\text { therapy }\end{array}$ & 1 year & $\begin{array}{l}\text { General Function Score (GFS); Back Pain; } \\
\text { Lower Limb Pain; Emotional Distress; Life } \\
\text { Satisfaction; Fear-avoidance physical activity; } \\
\text { Fear-avoidance work; Fingertip-floor distance; } \\
\text { Patient Overall Rating; Work Status. No } \\
\text { significant difference in GFS, back pain, lower } \\
\text { limb pain, emotional distress, life satisfaction, } \\
\text { patient overall rating and work status } \\
\text { Significant difference in fear avoidance, } \\
\text { physical and work and fingertip-floor distance } \\
\text { in favour of non-surgical group }\end{array}$ \\
\hline $\begin{array}{l}\text { Ekman et al. } \\
{[8], 2005 \text {, }} \\
\text { Sweden }\end{array}$ & $18-55$ & 106 & $\begin{array}{l}\text { PLF with or without } \\
\text { pedicle screws }\end{array}$ & $\begin{array}{l}\text { Physical } \\
\text { therapy }\end{array}$ & 2 years & $\begin{array}{l}\text { Pain Index; Disability Rating Index (DRI). } \\
\text { Significant difference in pain index and DRI in } \\
\text { favour of surgical group }\end{array}$ \\
\hline
\end{tabular}

scored greater than four points, with a score of four points or less indicating poor quality. Table 3 summarises the different criteria of study quality. All studies were prone to performance bias and detection bias since the intervention cannot be concealed and the outcome was a patientadministered questionnaire (ODI).
Quantitative results of the meta-analysis

Figure 2 displays the cumulative meta-analytic comparison. The mean overall difference in the ODI between the surgical and non-surgical groups was 4.13 in favour of surgery, but this difference was not statistically significant (95\%CI: -0.82 to $9.08, p=0.10$ ). There was evidence of

Table 2 Quality assessment ${ }^{\mathrm{a}}$ of randomised controlled trials

\begin{tabular}{|c|c|c|c|c|c|}
\hline \multicolumn{6}{|l|}{ Source } \\
\hline Type of bias & Item & $\begin{array}{l}\text { Fairbank } \\
\text { et al. [9] }\end{array}$ & $\begin{array}{l}\text { Fritzell } \\
\text { et al. [12] }\end{array}$ & $\begin{array}{l}\text { Brox } \\
\text { et al. [3] }\end{array}$ & $\begin{array}{l}\text { Ekman } \\
\text { et al. }[8]\end{array}$ \\
\hline \multirow[t]{2}{*}{ Selection } & Was allocation adequate? ${ }^{\mathrm{b}}$ & Yes & Yes & Yes & Yes \\
\hline & Was an adequate method of randomisation described? & Yes & Yes & Yes & Yes \\
\hline Performance & Were the patients/caregivers blinded to the intervention? ${ }^{\mathrm{c}}$ & No & No & No & No \\
\hline Detection & Was the outcome ascertained blindly? ${ }^{\mathrm{d}}$ & No & No & No & No \\
\hline \multirow[t]{2}{*}{ Attrition } & What percentage was lost to follow-up? & 19 & 2 & 3 & 5 \\
\hline & $\begin{array}{l}\text { Were all patients analysed in the group to which they } \\
\text { were assigned (intention-to-treat analysis)? }\end{array}$ & Yes & Yes & Yes & Yes \\
\hline
\end{tabular}

${ }^{\text {a }}$ Adapted from Juni et al. [17]

b Adequate" means the use of a central site, numeric code, opaque envelopes, drugs prepared by pharmacy and other appropriate procedures.

${ }^{\mathrm{c}}$ Unable to blind patient or caregiver due to nature of treatment

${ }^{\mathrm{d}}$ Outcome was a patient-administered questionnaire (ODI) 
Table 3 Quality assessment ${ }^{\mathrm{a}}$ of randomised controlled trials

Source

Criteria

Fairbank et al. [9] Fritzell et al. [12] Brox et al. [3] Ekman et al. [8]

Was there a randomisation method using an adequate procedure?

$\begin{array}{llll}\text { Yes } & \text { Yes } & \text { Yes } & \text { Yes } \\ \text { Yes } & \text { Yes } & \text { Yes } & \text { Yes } \\ \text { No } & \text { No } & \text { No } & \text { No } \\ \text { No } & \text { No } & \text { No } & \text { No } \\ \text { Yes } & \text { No } & \text { No } & \text { No } \\ \text { No } & \text { No } & \text { No } & \text { No } \\ \text { No } & \text { No } & \text { No } & \text { No } \\ \text { Yes } & \text { Yes } & \text { Yes } & \text { Yes } \\ \text { Yes } & \text { Yes } & \text { Yes } & \text { Yes } \\ \text { Yes } & \text { Yes } & \text { Yes } & \text { Yes } \\ 6 & 5 & 5 & 5\end{array}$

Was the treatment allocation concealed?

Was the care provider blinded to the intervention? ${ }^{\mathrm{b}}$

Was there control for co-interventions?

Were co-interventions reported for each group separately?

Was the patient blinded to the intervention? ${ }^{\mathrm{b}}$

Was the outcome assessor blinded to the intervention? ${ }^{\mathrm{c}}$

Was the withdrawal and drop-out $<20 \%$ short-term?

Was the timing of the outcome assessment in both groups similar?

Was the analysis done according to intention-to-treat?

Score $^{\mathrm{d}}$

6

${ }^{\text {a }}$ Adapted from van Tulder et al. [30]

${ }^{\mathrm{b}}$ Unable to blind patient or caregiver due to nature of treatment

${ }^{\mathrm{c}}$ Outcome was a patient-administered questionnaire (ODI)

${ }^{\mathrm{d}} \mathrm{A}$ score of 4 points or less indicates poor quality.

moderate heterogeneity between the studies, and the $\mathrm{I}^{2}$ was $44.4 \%$.

Figure 3 displays the cumulative early complication rate. Surgical treatment was associated with a $16 \%$ pooled rate of early complication (95\% CI: 12-20). No between-study heterogeneity was present, $\mathrm{I}^{2}=0 \%$. The study by Ekman et al. [8] had a lower complication rate of $4 \%$. The pooled rate of early complications following surgical treatment, including the Ekman et al. [8] study, was 13\% (95\%CI: 6-20, $\left.\mathrm{I}^{2}=66.9 \%\right)$.

\section{Results of sensitivity analyses}

Sensitivity analyses were performed to examine the effect of the imputed results from Fairbank et al. [9] and the inclusion of the study by Ekman et al. [8] in the analysis. Analysis using imputed results from Fairbank et al. [9] showed a mean overall difference in the ODI of 4.34 in favour of surgery, but this difference was not statistically significant (95\% CI: -0.48 to $9.17, p=0.08, \mathrm{I}^{2}=44.0 \%$ ).

Further analyses were carried out that included the study by Ekman et al. [8]. This latter study recruited patients with chronic low back pain caused by isthmic spondylolisthesis and was the only study to do so. Analyses including this study, using available or imputed results by Fairbank et al. [9], showed a mean overall difference in the ODI of 3.9 (95\% CI: $\left.0.17-7.62, p=0.04, \mathrm{I}^{2}=21.4 \%\right)$ and $4.11(95 \%$ CI: $0.46-7.76, p=0.03, \mathrm{I}^{2}=22.1 \%$ ) in favour of surgery, respectively.

\section{Discussion}

Our systematic review identified three randomised controlled trials that compared surgical fusion and non-surgical treatment for chronic low back pain and looked at the shortterm outcome. An additional study recruited a different patient group with isthmic spondylolisthesis and was included in the sensitivity analysis. All studies were of good methodological quality. The pooled results showed a trend in favour of surgery with a mean ODI difference of $4.13(p=0.10 ; 95 \% \mathrm{CI}:-0.82$ to 9.08$)$. The results were consistent across different assumptions. Analysis using imputed results from Fairbank et al. [9] caused minimal changes in the ODI mean difference between the groups (ODI difference $=4.34, p=0.08,95 \% \mathrm{CI}$ : -0.48 to 9.17 ). Sensitivity analyses that included the study of Ekman et al. [8] showed only minimal changes in the ODI mean

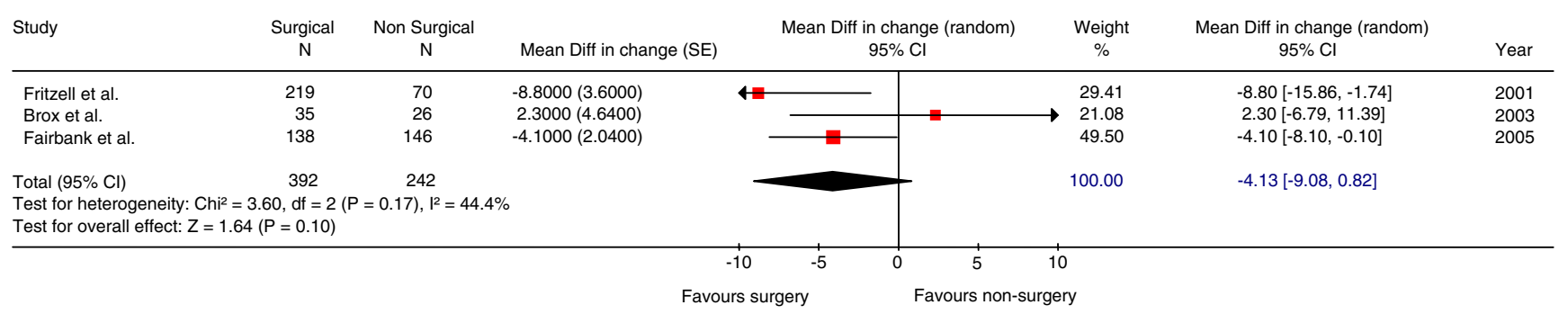

Fig. 2 Forest plot: mean difference in ODI and 95\% CI for surgical versus non-surgical treatment 


\begin{tabular}{|c|c|c|c|c|c|}
\hline Study & Complication rate (SE) & $\begin{array}{c}\text { Complication rate (random) } \\
\qquad 95 \% \mathrm{Cl}\end{array}$ & $\begin{array}{c}\text { Weight } \\
\%\end{array}$ & $\begin{array}{l}\text { Complication rate } \\
\text { (random) } 95 \% \mathrm{Cl}\end{array}$ & Year \\
\hline Fritzell et al. & $0.1754(0.0296)$ & - & 54.59 & $0.18[0.12,0.23]$ & 2001 \\
\hline Brox et al. & $0.1818(0.0882)$ & $\Longrightarrow-$ & 6.15 & $0.18[0.01,0.35]$ & 2003 \\
\hline Fairbank et al. & $0.1367(0.0349)$ & $\rightarrow$ & 39.27 & $0.14[0.07,0.21]$ & 2005 \\
\hline \multirow{2}{*}{\multicolumn{2}{|c|}{$\begin{array}{l}\text { Total }(95 \% \mathrm{Cl}) \\
\text { Test for heterogeneity: } \mathrm{Chi}^{2}=0.78 \text {, df }=2(\mathrm{P}=0.68), \mathrm{I}^{2}=0 \% \\
\text { Test for overall effect: } Z=7.34(\mathrm{P}<0.00001)\end{array}$}} & & 100.00 & $0.16[0.12,0.20]$ & \\
\hline & & & & & \\
\hline & & & & & \\
\hline
\end{tabular}

Fig. 3 Forest plot: early surgical complication rate and 95\% CI

difference (3.9) between the groups, which was statistically significant ( $p=0.04,95 \% \mathrm{CI}$ : $0.17-7.62)$.

All studies used a condition-specific validated patientadministered outcome measure - the ODI [10]. There is currently no consensus on what should be considered to be the clinically significant difference in the ODI from baseline to end point. Mead et al. [20] showed that a minimum ODI difference of four indicates clinical improvement, whereas Taylor et al. [28] suggested that a mean difference of 18 indicates clinical improvement. The upper level of the $95 \% \mathrm{CI}$ of the ODI difference in the pooled analysis was only 9.08. Surgical treatment was associated with a $16 \%$ pooled rate of early complication $(95 \% \mathrm{CI}$ : 12-20). From a clinical perspective, the overall complication rate of surgery outweighs this minimal clinical benefit.

The cost effectiveness of surgical versus non-surgical treatment of chronic low back pain has been reported for two of the studies in our meta-analysis. Fritzell et al. [11] found that the societal and health care costs for the surgical fusion patients was significantly higher than those for the non-surgical group. However, all treatment effects were better after surgical fusion. Rivero-Arias et al. [27] showed that surgical treatment cost twice as much as non-surgical intervention in the Fairbank et al. [9] study and that there was no statistical significance in the quality-adjusted life years between the groups.

The inclusion criteria and treatment modalities of each study were different, and these are potential sources of heterogeneity. In the Ekman et al. [8] study, the study population consisted of patients with isthmic spondylolisthesis. Möller et al. [25] reported similar clinical patterns and functional disabilities in patients with adult spondylolisthesis and low back pain of non-specific origin, while Fairbank et al. [9] used uncertainty of outcome as the eligibility criteria. The other two studies used pain for different time intervals: Fritzell et al. [12] recruited patients with back pain for at least 24 months, whereas Brox et al. [3] recruited patients with back pain for at least 12 months. The non-surgical intervention groups consisted of different treatment modalities. Fairbank et al. [9] and Brox et al. [3] used both physical therapy together with the principles of cognitive therapy, whereas Fritzell et al. [12] and Ekman et al. [8] used physical therapy alone. The compliance of physical therapy is also difficult to calculate and is likely to be different between the patient groups according to the intensity of the particular regime. Surgical treatment modalities also differed between the included trials. The fusion techniques used in the Fairbank et al. [9] study was left to the discretion of the surgeon. Several techniques must have been used, and this could be a potential source of heterogeneity.

Our analysis has limitations due to the paucity of studies addressing this pivotal issue. First, there were only three eligible published studies. Although there was moderate between-study heterogeneity, we chose to perform the meta-analysis to provide more generalisable results on the effect estimate. Second, the only outcome measure examined in this meta-analysis was the ODI. This is a reliable and clinically relevant outcome. Other important outcomes, such as patient satisfaction and return to work, were not included in all the original studies and thus were not considered for our meta-analysis. This may have limited our conclusions because it may not be possible to know whether patients achieved greater general health or higher satisfaction with or without surgery. The possibility that the observed improvement in the ODI between the surgical fusion and non-surgical groups was due to bias should be considered. It could be argued that this difference, although difficult to prove, could be due to the placebo effects of surgery following a procedure to treat a chronic symptom. Publication bias is also possible in our review. The small number of studies limits our ability to assess for (for instance, using a funnel plot) or draw conclusions regarding publication bias. Nevertheless, the expected direction of both placebo effect and publication bias towards the null effect strengthen our conclusion that currently available evidence does not support the routine use of surgery for the treatment of chronic low back pain.

\section{Conclusion}

We found that surgical fusion may improve the ODI compared to non-surgical intervention at the two-years follow-up for chronic low back pain. This improvement in the ODI was not statistically significant and is of minimal 
clinical importance; consequently, surgeons should recommend spinal fusion cautiously to patients with chronic low back pain. Further long-term follow-ups of the studies reviewed in this meta-analysis are required to provide more conclusive evidence in favour of either treatment.

\section{References}

1. Andersson GB (1999) Epidemiological features of chronic low pain. Lancet 354:581-585

2. Andersson HI, Ejlertsson G, Leden I, Rosenberg C (1993) Chronic pain in a geographically defined general population: studies of differences in age, gender, social class and pain localization. Clin J Pain 9:174-182

3. Brox JI, Sørensen R, Friis A, Nygaard Ø, Indahl A, Keller A, Ingebrigtsen T, Eriksen HR, Holm I, Koller AK, Riise R, Reikerås O (2003) Randomized clinical trial of lumbar instrumented fusion and cognitive intervention and exercises in patients with chronic low back pain and disc degeneration. Spine 28:1913-1921

4. Cherkin DC, Deyo RA, Loeser JD, Bush T, Waddell G (1994) An international comparison of back surgery rates. Spine 19:1201-1206

5. Christensen FB, Bünger C (2004) Stabilisation surgery for chronic low back pain: indications, surgical procedures, and outcome. Scand J Rheumatol 33:210-217

6. DerSimonian R, Laird N (1986) Meta-analysis in clinical trials. Control Clin Trials 7:177-188

7. Deyo RA, Gray DT, Krueter W, Mirza S, Martin BI (2005) United States trends in lumbar fusion surgery for degenerative conditions. Spine 30:1441-1445

8. Ekman P, Möller H, Hedlund R (2005) The long-term effect of posterolateral fusion in adult isthmic spondylolisthesis: a randomized controlled study. Spine J 5:36-44

9. Fairbank J, Frost H, Wilson-MacDonald J, Yu LM, Baker K, Collins R (for the Spine Stabilisation Trial Group) (2005) Randomised controlled trial to compare surgical stabilisation of the lumbar spine with an intensive rehabilitation programme for patients with chronic low back pain: the MRC spine stabilisation trial. Br Med J 330:1233-1239

10. Fairbank JCT, Pynsent PB (2000) The oswestry disability index. Spine 25:2940-2953

12. Fritzell P, Hägg O, Wessberg P, Nordwall A (2001) 2001 Volvo Award Winner in Clinical Studies: Lumbar fusion versus nonsurgical treatment for chronic low back pain. A multicenter randomised controlled trial from the Swedish Lumbar Spine Study Group. Spine 26:2521-2534

13. Fritzell P, Hägg O, Wessberg P, Nordwall A (2002) Chronic low back pain and fusion: a comparison of three surgical techniques. A prospective multicenter randomised study from the Swedish Lumbar Spine Study Group. Spine 27:1131-1141

11. Fritzell P, Hägg O, Jonsson D, Nordwall A (2004) Costeffectiveness of lumbar fusion and nonsurgical treatment for chronic low back pain in the Swedish Spine Study: a multicenter, randomized, controlled trial from the Swedish Lumbar Spine Study Group. Spine 29:421-434
14. Gibson JNA, Grant C, Waddell G (1999) The Cochrane review of surgery for lumbar disc prolapse and degenerative lumbar spondylosis. Spine 24:1819-1832

15. Herkowitz H (1995) Lumbar spine fusions in the treatment of degenerative conditions: current indications and recommendations. J Am Acad Orthop Surg 3:123-135

16. Higgins JP, Thompson SG, Deeks JJ, Altman DG (2003) Measuring inconsistency in meta-analyses. Br Med J 327:557-560

17. Juni P, Altman DG, Egger M (2001) Systematic reviews in health care: assessing the quality of controlled clinical trials. Br Med J 323:42-46

18. Kanwaldeep S, Herkowitz HN (1997) Spinal instrumentation in the management of degenerative disorders of the lumbar spine. Clin Orthop 335:39-53

19. Keller A, Brox JI, Gunderson R, Holm I, Friis A, Reikerås O (2003) Trunk muscle strength, cross-sectional area, and density in patients with chronic low back pain randomized to lumbar fusion or cognitive intervention and exercises. Spine 29:3-8

20. Meade TW, Dyer S, Browne W, Townsend J, Frank AO (1990) Low back pain: comparison of chiropractic and hospital outpatient treatment. Br Med J 300:1431-1437

21. Meta-analysis of change scores of the Cochrane Handbook (Section: 8.6.4.2). http://cochrane.dk/cochrane/handbook/8 analysing and_presenting_results/8.6_summarising_effects across_studies.htm

22. McAfee PC, Lee GA, Fedder IL, Cunningham BW (2002) Anterior BAK instrumentation and fusion: complete versus partial discectomy. Clin Orthop 394:55-63

23. Moher D, Cook JD, Eastwood S, Olkin I, Rennie D, Stroup DF (1999) Improving the quality of reports of meta-analyses of randomised controlled trials: the QUOROM statement. Lancet 354:1896-1900

24. Möller H, Hedlund R (2000) Surgery versus conservative management in adult isthmic spondylolisthesis. A prospective randomized study: Part 1. Spine 25:1711-1715

25. Möller H, Sundin A, Hedlund R (2000) Symptoms, signs, and functional disability in adult spondylolisthesis. Spine 25:683-689

26. Nachemson A (1985) Recent advances in the treatment of low back pain. Int Orthop 9:1-10

27. Rivero-Arias O, Campbell H, Gray A, Fairbank J, Frost H, Wilson-MacDonald $\mathrm{J}$ for the Spine Stabilisation Trial Group (2005) Surgical stabilisation of the spine compared with a programme of intensive rehabilitation for the management of patients with chronic low back pain: cost utility analysis based on a randomised controlled trial. Br Med J 330:1239-1243

28. Taylor SJ, Taylor AE, Foy MA, Fogg AJB (1999) Responsiveness of common outcome measures for patients with low back pain. Spine 24:1805-1812

29. Thomsen K, Christensen FB, Eiskjaer SP, Hansen ES, Fruensgaard S, Bünger CE (1997) 1997 Volvo Award winner in clinical studies. The effect of pedicle screw instrumentation on functional outcome and fusion rates in posterolateral lumbar spinal fusion: a prospective, randomised clinical study. Spine 22:2813-2822

30. van Tulder MW, Assendelft WJ, Koes BW, Bouter LM (1997) Method guidelines for systematic reviews in the Cochrane Collaboration Back Review Group for Spinal Disorders. Spine 22:2323-2330 